\title{
New Ideas for the Development of Tea Culture Tourism Economy in the Internet Age
}

\author{
Fei Deng ${ }^{1, *}$ \\ ${ }^{1}$ Jiangxi Industrial and Polytechnic College, Nanchang, Jiangxi, China,330029
}

\begin{abstract}
Tea originated in China and flourished in China. Tea has a long history for China. Tea has given birth to rich history and culture in the long river of history. Tea culture has become an important part of our excellent traditional culture, which has given birth to countless traditional cultural industries. Although with the development of the times, Chinese traditional cultural industry is facing many challenges. Fortunately, the arrival of the information age has brought new opportunities for the traditional cultural industry. This paper analyzes the new ideas brought by the era of "Internet" for the development of tea culture tourism economy, and discusses how to better use information technology to help the development of traditional cultural industry.
\end{abstract}

\section{INTRODUCTION}

The rise of tea culture tourism economy is actually the way to innovate Chinese traditional culture. Under the background of "Internet ", the related tea culture tourism enterprises should change the traditional concept, innovate the thinking mode, and look at the vitality and creativity brought by information technology to the tea culture tourism industry from the perspective of development. Tea culture tourism enterprises can provide more new ideas for the development of tea culture tourism economy with the help of Internet technology. At present, the enterprise should correctly understand Internet technology, absorb more highquality technical talents, and scientifically explore the development of tea culture tourism. Tea culture tourism enterprises can not only promote the rapid development of tea culture tourism economy, but also better spread our excellent traditional culture.

\section{AN OVERVIEW OF TEA CULTURE TOURISM}

China is the hometown of tea. Chinese tea is the production of labor, is a kind of grade promotion, its history is long, contains profound cultural background. Tea culture takes tea as the carrier and spreads all kinds of art through this carrier. Tea culture is the organic fusion of tea and culture. This includes and embodies a certain period of material civilization and spiritual civilization. With the change and development of society, tea and some habits in Chinese life are merged, forming various cultural phenomena with Chinese characteristics. Tea culture is a representative traditional culture in China. Nowadays, Chinese tea is not only widely popular all over the world, but also widely integrated into various cultural industries to create more cultural value.

In recent years, the improvement of people's living standard has made the tourism industry develop rapidly. With the increasingly fierce market competition, tourism enterprises continue to innovate, there is a tea culture tourism characteristics. Tea culture and tourism linked, constantly for tourism innovation and development, tourism enterprises continue to increase income. The characteristic tea culture tourism takes the tea production place as the activity center, opens the tourist attraction, provides the traveling activity item, attracts the tourist to go. This tourism activity can not only promote the traditional tea culture of China, but also help the development of tea industry, innovate the tourism culture industry and promote the sustainable development of tea culture tourism economy[1].

Tea culture tourism also has distinct characteristics, summarized as follows:

\subsection{Seasonal Tourism of Tea Culture}

Tea has its unique seasonality from planting, picking, drying and making tea, which also makes tea culture tourism have certain time limit. In most cases, the season of tea culture tourism is when tea grows luxuriantly, or it is in the tea picking period, which can not only make the tourism have a certain scenery appreciation, but also obtain fresh tea in the tea picking period. But this kind of seasonal tourism has become a major limitation that hinders the development of tea culture tourism. But if the Internet technology, the establishment of online tourism platform, but can greatly improve this problem, with the help of Internet technology, so that the beautiful scenery stay online, tourists can browse through the network

*Corresponding author's e-mail: 739960103@qq.com 
platform, get visual "tourism ", Let the tourism experience no longer be limited by the season.

\subsection{Regional Tourism of Tea Culture}

In general, the location of tea culture tourism is mostly in the tea production site or tea start-up garden base, which also makes tea culture tourism regional. Most of the projects of tea culture tourism are tea scenic spot viewing, tea making experience, tea tasting, learning tea culture and so on. These all need to rely on the origin of tea to provide a more characteristic tea culture. However, some places of origin are restricted by region. Due to economic, transportation and other problems, it is difficult to provide good tourism service infrastructure, which will greatly reduce the tourist experience. However, with the help of the Internet platform, it can greatly change the regional limitations of tea culture tourism. Through computer technology, the construction of network virtual tourism platform, coupled with the use of a wide range of three D of technology, for tourists to build an online tourism, online learning platform, can greatly improve the tourism industry by limitations. The way of online tourism also attracts tourists to the real scene to a certain extent, thus driving the development of field tea culture tourism[2].

\subsection{Humanism of Tea Culture Tourism}

Tea culture tourism audience is more tea lovers, the tourism is also very strong humanistic heritage. To promote the spread of culture in tourism, on the one hand, make the tourism meaningful, on the other hand, let Chinese traditional culture go out in a better way. Moreover, the Internet platform also provides more possibilities for cultural communication, and more groups can come together through the Internet platform because of the same hobbies. They can communicate on the platform and discuss tea culture, which not only promotes the exchange and development of tea culture, but also brings more tea culture lovers to join the group of tea culture tourism.

\section{The Value Analysis of "Internet" on Tea Culture Tourism Industry}

\subsection{Promoting the Economic Development of Tea Culture Tourism Industry}

Tea culture tourism is a kind of leisure and entertainment experience of sightseeing, but in the case of underdeveloped information technology before, tea culture tourism lacks relatively complete tourism service facilities. With the rapid popularization of information technology, tea culture tourism industry has gradually developed with the help of Internet technology. Because the audience of tea culture tourism project in China is relatively small, coupled with the fierce competition of tourism industry in the market, it is impossible to survive in the tourism market without complete and good tourism service facilities. But now, the audience of Internet technology is very wide, and the speed of information dissemination is very fast, which has great advantages for tourism industry. With the help of network information platform, the industry can increase publicity, raise popularity, increase passenger flow and ensure the income of tourism industry, so as to invest more funds for tourism industry and perfect the infrastructure construction of tourism service. Optimize industrial structure and promote the sustainable development of tea culture tourism industry[3].

\subsection{Innovation of Development of Tea Culture Tourism}

Today, the Internet is widely used, collecting countless resources around the world to form a huge database. The Internet has built a global village so that every place in the world is not a closed space. It is this open information technology that provides more reference models for the construction of tea culture tourism. Tea culture tourism enterprises can absorb and learn from the tourism culture around the world through the Internet platform and innovate their own tea culture tourism industry. At the same time, the tea culture of China is unique, its cultural background is extensive and profound, through the local thought fusion, opens up more new ideas for the tea culture tourism development.

\subsection{Broaden the Development Approach of Tea Culture Tourism Industry}

Nowadays, most tourism enterprises pay more attention to the popularity of tourism industry. Most tourism companies continue to strengthen the publicity and marketing of the industry while opening up tourism projects. But still only for tea production and tea sales focus on publicity. Although this kind of propaganda has certain effect, but only meets the demand of some sales people, is not enough to promote the development of this industry. In the face of increasingly fierce competition in the market, if only repeat the inherent way of tourism, it will gradually make consumers lose their freshness and appear the phenomenon of economic decline in tourism industry. On the basis of the Internet, a network information platform is established. Tourism companies can use the network information platform to establish a unique tea culture tourism network platform to provide consumers with a more complete and multi-faceted introduction of tea culture tourism information. In order to improve the publicity of the industry. The tourism industry company can also create a virtual cyberspace to provide consumers with the opportunity to choose their own, the consumer can use the network platform to create their own satisfied tourism projects. According to this idea, it can effectively broaden the development of tea culture tourism industry, and promote the development of tea culture tourism industry with the help of Internet technology. 


\section{The Present Situation of Tea Culture Tourism Economy in the Context of Internet}

Although with the help of Internet technology, the tourism economy of tea culture has been developed to a certain extent, it is only the innovation of tourism mode, the optimization of industrial structure and the perfection of infrastructure. At present, there are still some problems in the tea culture tourism industry, and these problems are the important reasons that hinder the development of the tourism[4].

\subsection{Insufficient publicity for innovative Internet}

Although with the help of Internet platform, tourism projects and tourism products have been promoted and sold, which also makes tourism enterprises obtain good economic benefits. But if it is limited to one way of propaganda, it will make the promotion of tourism consumption problems, make product consumption difficult, and make the development of the industry stagnant. Due to the short time of the Internet, the related tea culture tourism enterprises do not understand it. Tea culture tourism enterprises pay less attention to the coverage and influence of the Internet, so that the industry only stays at the level of advertising with the help of Internet technology, neglects to optimize its own conditions, and innovates the "Internet" propaganda mode. The online propaganda of the Internet should not only rely on advertising promotion, but also use the promotion skills of the network information platform, combine its own advantages, constantly innovate the propaganda mode of the cultural tourism, and promote the sustainable development of the tea culture tourism economy.

\subsection{The audience of tourism is small and the development prospect is narrow}

Nowadays, the cultural tourism is influenced by the tea production area and has certain regional characteristics. In China, the production area of tea is wide and the origin is scattered, which makes the related tea culture tourism enterprises belong to the mode of decentralized management, and the development of the tourism project is mainly concentrated in the surrounding development of tea. Under the influence of these factors, the market of the tourism enterprise is narrow and the consumer product is single, which makes it difficult for the tea culture tourism enterprise to get broad development space and to base itself on the tourism market[5].

\subsection{The tour's brand awareness is low and its influence low}

In the consumer market, good product sales and good service reputation are important factors to promote the continuous development of industrial economy. In China, the tea producing area is broad and scattered, which also derives many related cultural tourism enterprises, but all lack a strong influence brand. The dispersion of enterprises makes the enterprises lack of cooperation and communication, their respective business models are different, it is difficult to gather the advantages and help the cultural tourism industry to base itself on. Therefore, in order to increase the brand awareness of this culture, we should strengthen the cooperation and exchange among enterprises, pool our wisdom, concentrate our advantages and build a good infrastructure platform. Strengthen the influence of the tourism project in the international market.

\subsection{The activity of the tour is single and the service experience of the tourists is low}

Nowadays, the tea culture tourism enterprise has a low degree of development of such tourism activities. In terms of product sales, the enterprise is limited to the sale of tea, and the tour itinerary is arranged for more sightseeing in the tea base. In the dissemination of tea culture knowledge, only through knowledge explanation, participation in the tea making process, appreciation of tea performances, Can not really attract tourists to. And the production of tea, mostly in more remote areas. Under the influence of local economic level, local transportation restriction and enterprises' insufficient attention to innovation and development, the tourism service infrastructure of the industrial base is not perfect enough, which will greatly reduce the satisfaction of tourists' service experience in tourism.

\section{The Present Situation of Tea Culture Tourism Economy in the Context of Internet}

Under the background of "Internet ", the ideas of the development of tea culture tourism economy can be carried out from the following aspects:

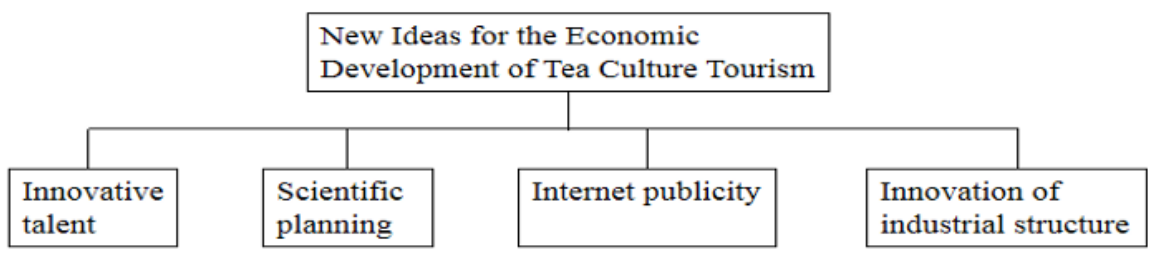

Fig. 1. New Ideas for the Economic Development of Tea Culture Tourism 


\subsection{Tea culture tourism enterprises can recruit high-quality innovative talents}

The development of enterprises needs to constantly inject new vitality, and employees are the source of vitality. High-quality innovative talents are an important part of promoting the development of enterprises. Under the background of the development of information technology, the tea culture tourism company is in urgent need of technical talents who are good at the Internet and create a talent reserve team with innovative vitality. With the help of new talent team, using Internet technology, innovating enterprise culture tourism projects, enhancing the competitiveness of enterprises in the market, promoting the rapid development of tea culture tourism economy. Due to the lack of understanding of Internet technology and the neglect of high-quality technical talents on the Internet, the tourism company of China lacks this talent team. At present, the relevant tourism company should change the traditional thinking innovation management mode in time, actively invest in the talent market, recruit applied talents with Internet technical knowledge, and conduct centralized training. Enhance its ability to use Internet technology to develop tourism projects and innovate sales methods, and inject new vitality into the sustainable development of tea culture tourism enterprises[6].

\subsection{Tea culture tourism enterprise should make more comprehensive and scientific development policy with the help of Internet technology}

At present, the development of tea culture tourism enterprises in China is scattered, and the management modes of each enterprise are different, so the development of tea culture tourism industry is more chaotic. Therefore, solving the chaos of the tourism industry is the most important issue. Each cultural tourism enterprise in China should change the traditional management idea, increase the cooperation between enterprises, and make reasonable development plan with the help of Internet platform. The development of tea culture tourist attractions is closely related to the natural environment. If the two fail to reach a reasonable arrangement, they will conflict. This requires enterprises to have the consciousness of protecting the environment and develop reasonably on the basis of not destroying the natural balance. This requires enterprises to have scientific development planning, with the help of Internet information collection platform, clearly know which resources are available, which are protected resources, to legally develop. Scientific and reasonable development plan can help the orderly development of tourism enterprises and help enterprises to devote themselves to nature protection. Kill two birds with one stone, why not do it.

\subsection{Tea culture tourism enterprises can strengthen innovation construction with the support of government departments to cultural industry}

China is an ancient country with a long history and deep cultural background. Tea culture is an important part of our traditional culture. In order to keep the excellent traditional culture alive, the government attaches great importance to the development of this culture. The emergence of the Internet, for the innovation and development of enterprises to provide new vitality. However, opportunities and challenges coexist, and traditional tea culture tourism enterprises face great challenges in the strong information dissemination ability of the Internet. With the help of Internet technology, the new tourism culture industry expands the propaganda of the related tourism project, innovates the tourism mode, and makes use of the combination of online and offline management mode, which undoubtedly makes the traditional tourism industry face the crisis of survival. In order to change this unfavorable phenomenon, the tourism industry of traditional tea culture needs to learn Internet technology, innovate the development mode of this industry and move forward with the new industry with the help of the government's support to the traditional cultural industry[7].

\section{Conclusion}

In general, through the exploration of new ideas for the development of tea culture and economy in the "Internet" era, this paper finds that the Internet era brings many new creativity to the traditional cultural industry. The Internet plays an important role in the innovation, dissemination and sale of tea culture tourism projects. Therefore, the cultural tourism industry should realize the organic combination of Internet and tea culture tourism development, and promote the rapid development of tea culture tourism economy.

\section{References}

1. Wang,J.H.Zhang,S.Y.Zhou,H.Y.(2020)New Ideas for the Development of Tea Culture Tourism Economy in the Internet Age.Fujian tea.7:113-115.

2. Wu,K.L.Li,R.Y.(2017)New Ideas for the Development of Tea Culture Tourism Economy in the Internet Age.Fujian tea.6:125-127.

3. Huang,Z.S.(2018)Trends and Strategies of Cultural Tourism Communication of Ancient Capital in the Age of Internet.Urban observation.6:145-151.

4. Liao,S.Y.(2019)Analysis on the Economic Development of Tea Culture Tourism in the Era of Internet.Fujian tea.6:65-66.

5. He,Y.Zhao,A.Y.(2019)Research on the Integration of Tea Culture Tourism Industry in Internet Age.Fujian tea.1:108-109. 